\title{
El ciclo pictórico del Colegio de Teólogos de San Isidoro de Murcia atribuido a Vicente Inglés
}

\section{The Pictorial Cycle of the College of Theologians of Saint Isidore of Murcia attributed to Vicente Inglés}

\author{
Pedro Martínez CaVERo \\ Universidad de Murcia *
}

\begin{abstract}
Resumen: El Colegio de Teólogos de San Isidoro es una de las fundaciones realizadas en la ciudad de Murcia por el cardenal Luis Belluga en el siglo XVIII. Para ornamento de la capilla del Colegio se concibió un ciclo pictórico, atribuido al pintor valenciano Vicente Inglés, realizado a mediados del siglo XVIII. Tras la desamortización del edificio, este legado pasó a formar parte del patrimonio del Instituto Provincial de Segunda Enseñanza de Murcia y hoy se conserva en la sede del Instituto Alfonso X el Sabio.
\end{abstract}

Palabras clave: Vicente Inglés, Pérez Truyol, Sístori, Javier Fuentes y Ponte, San Felipe Neri, San Francisco de Sales, Santa Irene, San Alejo, San Juan Nepomuceno.

Abstract: The College of Theologians of Saint Isidore is one of the foundations carried out by Cardinal Luis Belluga in the city of Murcia in the 18th century. A cycle of paintings attributed to the Valencian painter Vicente Inglés was conceived in the mid-18th to decorate the College chapel. After the confiscation of the building, this artistic legacy became part of the heritage of the Provincial Institute of Second Education of Murcia and nowadays it is preserved in the Alfonso X el Sabio Secondary Institute.

Key words: Vicente Inglés, Pérez Truyol, Sistori, Javier Fuentes y Ponte, Saint Philip Neri, Saint Francis of Sales, Saint Irene, Saint Alexis, Saint John of Nepomuk.

\footnotetext{
* Recibido: 10 de junio de 2018. Aceptado: 10 de septiembre de 2018.

Email: pmcavero@um.es. Los resultados de este trabajo fueron adelantados en la conferencia pronunciada por el autor en la Real Academia Alfonso X el Sabio el 23 de mayo de 2018.

http://dx.doi.org/10.6018/rmu/355501
} 


\section{INTRODUCCIÓN}

Se ha cumplido el doscientos cincuenta aniversario de la inauguración oficial en 1767 del Colegio de Teólogos de San Isidoro de Murcia, para cuya capilla se concibió un ciclo pictórico atribuido al pintor de origen valenciano Vicente Inglés. En este trabajo estudiamos las transformaciones que sufrió dicha capilla en los siglos XIX y principios del XX, tras la conversión del edificio en el Instituto Provincial de Segunda Enseñanza de Murcia, así como la disposición de los cuadros del ciclo pictórico. Contamos para ello con la obra del erudito murcianista Javier Fuentes y Ponte, quien en 1882 describió la capilla en su España Mariana. Provincia de Murcia, una obra que, en este tema, no ha sido tenida en cuenta hasta ahora por la historiografía. Su valor, sin embargo, es muy importante, pues Fuentes y Ponte describió con minuciosidad y maestría los cuadros de la capilla y su distribución en la nave, ubicación que el paso del tiempo ha hecho desaparecer y que reconstruimos en este trabajo. Las obras de arte de la antigua capilla se conservan hoy en el Instituto Alfonso X el Sabio de Murcia, heredero de aquella institución.

\section{EL COLEGIO DE TEÓLOGOS DE SAN ISIDORO. FUNDACIÓN Y DESAMORTIZACIÓN}

Situado en el entorno de la catedral de Murcia, la historia del Real Colegio de Teólogos de San Isidoro está unida en muchos aspectos a la historia de la ciudad de Murcia. Se levantó a continuación del Seminario de San Fulgencio, entre éste y el hoy desaparecido Hospital de San Juan de Dios, y su erección está vinculada al gobierno de tres importantes obispos de la diócesis de Cartagena: Luis Belluga, Juan Mateo y Diego de Rojas. ${ }^{1}$

La idea de la fundación del Colegio correspondió al obispo Luis Belluga (1704-1724), más tarde cardenal en Roma hasta su fallecimiento el 22 de febrero de 1743. Como es conocido, el Colegio de Teólogos es una de sus cuatro Pías Fundaciones, dedicadas a los cuatro santos cartageneros: El Seminario de San Fulgencio, el Colegio de Teólogos de San Isidoro, el Colegio de San Leandro y la Casa de la Misericordia de Santa Florentina.

1 En el Palacio Episcopal se conservan los retratos de estos tres obispos, obra del pintor Pablo Pedemonte, que originalmente fueron pintados para el Colegio de Teólogos. Huellas. Catedral de Murcia. Exposición 2002, Murcia: Caja de Ahorros de Murcia, 2002, pp. 237, 239 y 240. 
El edificio del Colegio de Teólogos se levantó durante el episcopado de Juan Mateo (1742-1752), uno de los grandes constructores del siglo XVIII, que asumió los ambiciosos proyectos de Belluga. Impulsó la creación del nuevo Palacio Episcopal, del Seminario de San Fulgencio y remodeló su entorno. Las obras estuvieron a cargo de los arquitectos Martín Solera y Pedro Pagán. A este propósito, Díaz Cassou recoge el dato de que «en 1750 fueron cortadas en los montes de Caravaca las maderas para el Colegio de San Isidoro, de Murcia». ${ }^{2}$ Al morir el prelado en 1752, los trabajos, que estaban casi acabados, se interrumpieron durante algunos años.

El edificio se terminó de construir a lo largo de 1766, durante el episcopado de Diego de Rojas y Contreras (1753-1772), y fue inaugurado oficialmente el 1 de enero de 1767, en el reinado de Carlos III y tres meses antes de la expulsión de los jesuitas. El decreto de erección fue firmado por el obispo Rojas el 17 de diciembre de 1766 y se leyó en el altar de la capilla del Colegio el citado 1 de enero del nuevo año.

\footnotetext{
«Erigimos, instituimos y establecemos (...) conforme a la disposición y Decreto latino del Eminentísimo Señor Cardenal Don Luis de Belluga y Mocada (...) y le dedicamos la capilla al Señor San Ysidoro Confesor, Pontífice y Doctor (...). Y mandamos colocar su Ymagen según la hemos hecho pintar en el principal altar de la Capilla». ${ }^{3}$
}

La «ymagen» del titular se atribuye al pintor valenciano Vicente Inglés, así como un ciclo pictórico compuesto por otras seis obras - de las que nos ocupamos en este trabajo-, que irían colocadas en las capillas laterales.

La fecha de inauguración del Colegio, 1767, es confirmada igualmente por Andrés Baquero Almansa, que la lee en una inscripción fundacional (monumentum aedificationis) que había en el remate del retablo pintado por el muralista Pablo Sistori en la pared del altar mayor: «Por un tarjetón de su rematé, sabemos que dicha capilla se terminó en el año 1767 , en el pontificado de D. Diego de Roxas». ${ }^{4}$

2 P. Díaz Cassou: Serie de los obispos de Cartagena, Murcia, 1859, p. 192. Sobre su sucesor, Diego de Rojas, afirma, p. 197: «continúa las apenas empezadas obras del Colegio Real de Teólogos de San Isidoro».

3 F. Arnaldos Martínez: «El colegio de teólogos de San Isidoro de Murcia», Scripta Fulgentina, 18, 2008, pp. 141-167; p. 150, AHN, Consejos, leg. 5.495, Erección del Colegio de S. Isidoro, Murcia, 17-12-1766, ff. 30v.-31r.

4 A. Baquero Almansa: Los Profesores de las Bellas Artes Murcianos, Murcia, 1913, pp. 271 272. 
El Colegio de Teólogos estaba destinado a que seminaristas escogidos de San Fulgencio pudieran ampliar en él su formación, que constaría de entre cinco y siete cursos de Teología. No obstante, estos estudios no se practicaron durante mucho tiempo, pues la vida del Colegio fue muy breve, apenas medio siglo. A principios del XIX sufrió los efectos de la Guerra de la Independencia, resultado de la cual fue clausurado en 1810. San Isidoro se convirtió entonces en un cuartel destinado a estacionar tropas para defender Murcia en caso de ataque francés, en escuela de cadetes, almacén de víveres y corrales, durante algo más de dos décadas. Como consecuencia de estos estragos, el edificio llegó a encontrarse en un estado deplorable, casi ruinoso, y fue incluido en el conjunto de bienes objeto de la Desamortización eclesiástica de Mendizábal de 1836. Al año siguiente, transformó su utilidad al crearse el Instituto Provincial de Segunda Enseñanza y establecerse en él su sede.

El Instituto Provincial de Murcia se creó en 1837 a instancias del gobernador de la provincia Agustín Álvarez Sotomayor. Fue fundado por una Real Orden de 5 de octubre de dicho año. Funcionaría con las rentas de los bienes procedentes de la Desamortización, que entonces eran muy cuantiosas. ${ }^{5} \mathrm{Su}$ primer director efectivo fue el canónigo Pedro Andrés Alonso-Builnes. Desde su creación y hasta la fundación de la Universidad de Murcia, el Instituto Provincial se convirtió en el máximo referente de la enseñanza pública en el territorio murciano. El curso inaugural, en 1838, se inició en San Fulgencio, pues el edifico se encontraba muy deteriorado y necesitaba reformas y reparos. Muy poco después, en septiembre de 1840, fruto de los avatares de la política nacional que dieron paso a la Regencia del general Espartero, la Junta Provincial de Murcia transformó el Instituto en Universidad Literaria - con estudios de Leyes, Medicina y Filosofía-, aunque esta situación sólo duró un año.

Veinte años más tarde, en 1860, se llevó a cabo una gran remodelación del edificio, tutelada por su director Ángel Guirao Navarro. Guirao fue un político conservador y naturalista de fama internacional. ${ }^{6}$ Ejerció durante treinta años de director del Instituto (1857-1887). Su reforma debió tener presente la entonces reciente Ley Moyano (1857), que regulaba la segunda enseñanza.

5 P. Segura Artero: «La época de fundación», en R. Jiménez Madrid (coord.): El instituto Alfonso X el Sabio: 150 años de historia, Murcia: Editora Regional, 1987, p. 73-85, expone los bienes y rentas del Instituto.

6 F. López Azorín: Murcia y sus científicos en la Real Sociedad Española de Historia Natural (1871-1940), Murcia: Fundación Séneca, 2012, pp. 101-110. E. RosSMÄSSLER: Recuerdos de un viajero por España, Madrid: Consejo Superior de Investigaciones Científicas, 2010, p. 167, comenta sobre su labor científica: «Desgraciadamente, Guirao no encuentra ningún apoyo en sus paisanos, ni interés alguno en la investigación de la Historia Natural de su provincia; en cambio, a menudo es tratado como un loco, porque como naturalista gasta demasiado tiempo, dinero y trabajo en cosas 'inútiles'!». 
Con respecto a la antigua capilla del Colegio de Teólogos, la adaptó para su utilización como salón de actos, si bien conservó los altares laterales. Su principal actuación fue la modificación de la puerta de acceso a la capilla y presumiblemente el cambio del altar mayor del testero norte al sur, como veremos. Hay que pensar en la preeminencia de la puerta norte, ubicada en la plaza de San Juan de Dios -actual calle Eulogio Soriano-, que es la más próxima a la catedral. Desde esta puerta -describe Javier Fuentes y Ponte- se accede al vestíbulo y, a continuación, se ascienden cuatro peldaños para ingresar en un pequeño patio que servía de antecapilla, cuya puerta había sido tapada con las reformas y sustituida por la nueva puerta abierta en el lado Este del claustro, «inutilizando el primer altar del lado derecho». ${ }^{7}$ Todas estas transformaciones podemos observarlas en los planos que mandó levantar el director Ángel Guirao con motivo de su reforma del edificio. ${ }^{8}$

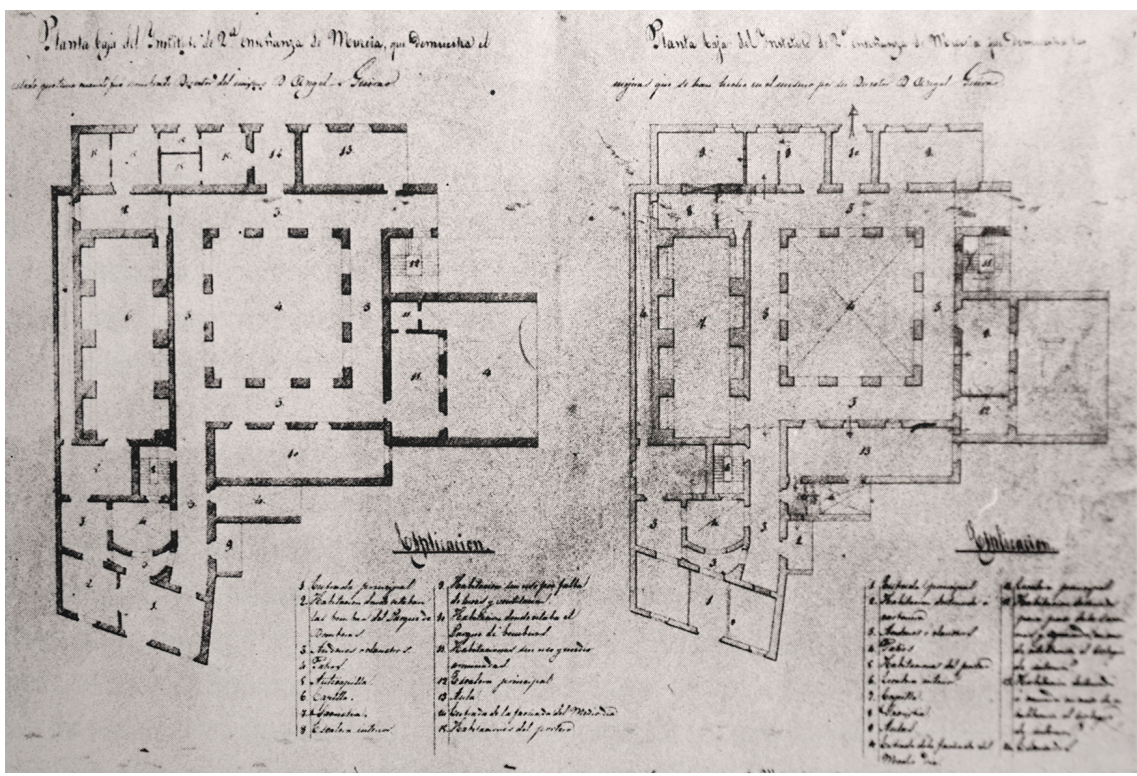

Figura 1. Reforma de 1866 durante la dirección de Ángel Guirao. Se aprecia la modificación del acceso a la capilla.

«Ya en el vestíbulo, hay que subir otros cuatro peldaños para subir a un pequeño patio que servía de antecapilla, y con las reformas ha sido tapada la puerta de ésta (...). En el lado E de dicho claustro se halla la nueva puerta de la Capilla, rasgada al efecto, inutilizando el primer altar del lado derecho» (Fuentes y Ponte).

7 J. Fuentes y Ponte: España Mariana. Provincia de Murcia, Lérida: Impr. Mariana, 1880-84, p. 53.

8 P. Segura Artero: «La época de fundación», en R. JimÉnEZ MADrid (coord.): El instituto Alfonso X el Sabio, 1987, p. 83. 
No obstante, la reforma más importante que sufrió la capilla tuvo lugar en 1906 siendo director Andrés Baquero Almansa (1904-1915). Baquero había accedido a la dirección del Instituto en 1904 y contaba con el apoyo y la amistad de importantes políticos murcianos, como Antonio García Alix y Juan de la Cierva Peñafiel, en distintos momentos ministros del gobierno central. Baquero abandonó la dirección del Instituto en 1915 al ser nombrado Comisario Regio durante el proceso de fundación de la Universidad de Murcia, de la que fue, por lo tanto, su primer rector. ${ }^{9}$

La reforma de Baquero afectó particularmente a la capilla, que fue transformada definitivamente en salón de actos. En ese momento, como veremos, los altares laterales fueron anulados como tales y de ellos retiradas las pinturas, que perdieron su ubicación primitiva. El salón de actos fue redecorado en estilo ecléctico, se reconstruyó el techo imitando un artesonado y se pintó una «Galería de Murcianos Ilustres» con personajes de la política, de las artes y de las letras. Los retratos fueron realizados por el pintor Antonio Meseguer y representan dieciséis personalidades murcianas desde el siglo XV a su propio tiempo, principios del siglo XX. El conjunto se compone de dos series de ocho personajes. La primera, formada por cronistas y literatos, artistas y políticos: Rodríguez Almela, Ramírez Pagán, el Licenciado Cascales, Saavedra Fajardo, Polo de Medina, Salzillo, Floridablanca y Diego Clemencín. La segunda serie se compone de escritores, científicos y políticos relacionados con la historia del Instituto que, recordamos, era en ese momento la principal institución académica murciana: Ángel Guirao, Francisco Cánovas Cobeño, José Selgas, Federico Balart, Lope Gisbert, José Echegaray, Antonio García Alix y Juan de la Cierva Peñafiel.

Durante ciento treinta años el edificio del Colegio de Teólogos fue la sede del entonces llamado «Instituto de Murcia», que adaptó su nombre a las distintas leyes educativas, denominándose sucesivamente Instituto Provincial de Segunda Enseñanza, Instituto General y Técnico, y, desde 1939, Instituto Alfonso X el Sabio. Con posterioridad, en el inmueble del Colegio de Teólogos se ubicó el Instituto Saavedra Fajardo y hoy lo ocupa el IES Licenciado Cascales. ${ }^{10}$ En 1982 fue incoado expediente de declaración de monumento histórico-artístico a favor

9 J. A. Ayala: «Andrés Baquero y la proyección cultural del Instituto en Murcia (1904-1915)», en R. Jiménez Madrid (coord.): El Instituto Alfonso X el Sabio... 1987, pp. 165-197.

10 Estas denominaciones de los centros independientemente de su carácter de «Instituto Nacional de Bachillerato», «Instituto de Enseñanza Media» o «Instituto de Enseñanza Secundaria». El IES Licenciado Cascales fue originalmente el Instituto número 6 de Murcia. 


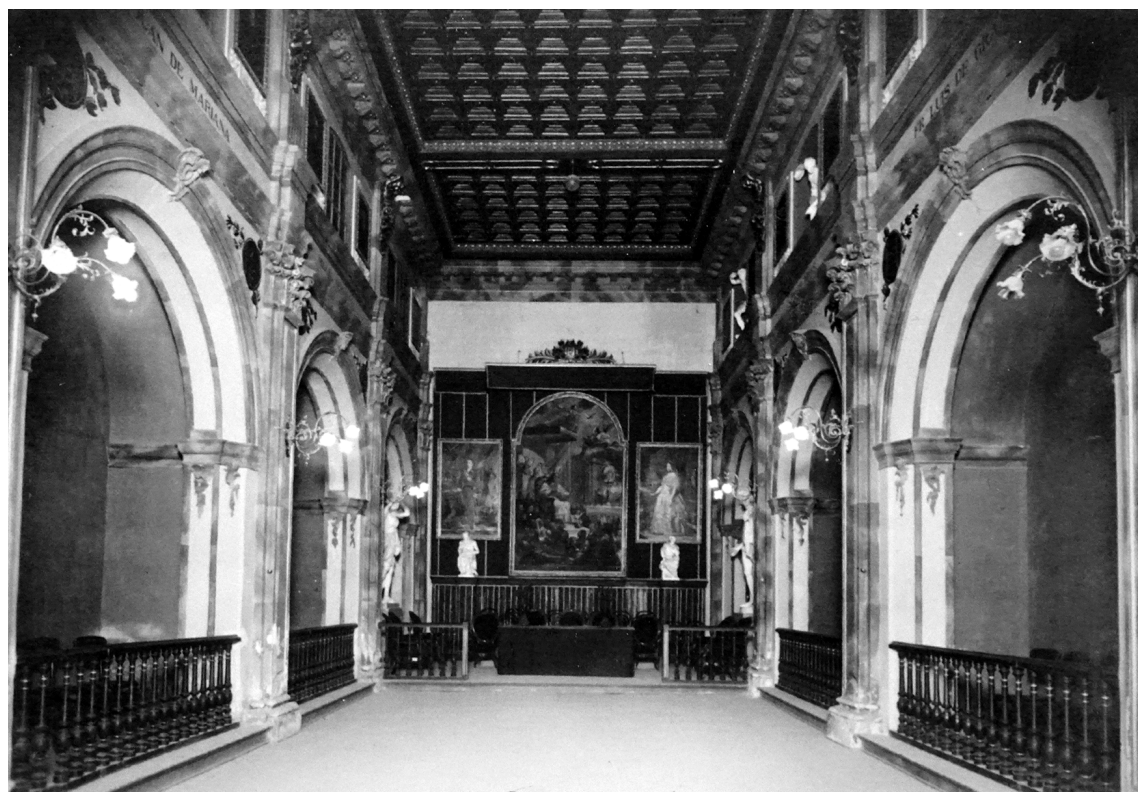

Figura 2. Reforma de 1906 durante la dirección de Andrés Baquero. La antigua capilla del Colegio de Teólogos se transformó definitivamente en salón de actos. Se redecoró en un estilo ecléctico, se construyó el artesonado y se pintó la Galería de Murcianos Ilustres. Las pinturas de las capillas laterales no se encuentran en su ubicación primitiva. (Fotografía: Exposición Archivo Regional, 2018).

del edificio del antiguo Colegio de Teólogos y, en 2018, ha sido declarado bien de interés cultural con categoría de monumento. ${ }^{11}$

\section{ESTUDIOS SOBRE EL CICLO PICTÓRICO}

La vida y la obra de Vicente Inglés son aún insuficientemente conocidas. Los datos que aquí anotamos proceden de la historiografía, pues queda aún mucho por investigar sobre su trabajo y su estancia en la capital murciana.

En primer lugar, Vicente Inglés aparece referenciado en 1871 en la Murcia artística de Juan José Belmonte, que es quien le atribuye la autoría de las pinturas de la capilla. Esta misma opinión sostienen Pedro Díaz Cassou en 1895 y

11 Resolución de 22 de enero de 1982 de la Dirección General de Bellas Artes, Archivos y Bibliotecas, BOE, 26 de marzo de 1982, n. 73, pp. 7882-7883. Decreto n. ${ }^{\circ}$ 5/2018, de 24 de enero, del Consejo de Gobierno de la Comunidad Autónoma de la Región de Murcia, BORM, 29 de enero de 2018, pp.1875-1879. 
Andrés Baquero Almansa en 1913.12 En 2002 los cuadros fueron restaurados por el Centro de Conservación y Restauración de Bienes Culturales de la Región de Murcia $^{13}$ y en 2003 la Academia Alfonso X el Sabio publicó un importante trabajo sobre el ciclo y la obra artística de Vicente Inglés: Un programa docente del s. XVIII en Murcia. El pintor Vicente Inglés, debida a Gracia Ruiz Llamas y David López García. ${ }^{14}$

Sin embargo, estos últimos trabajos no han tenido en cuenta la descripción que de la Capilla del Colegio de Teólogos realizó el erudito murciano Javier Fuentes y Ponte y que publicó en su España Mariana. Provincia de Murcia (18801884). ${ }^{15}$ No obstante, hacemos notar que esta obra fue leída y seguida por Andrés Baquero - que escribe tres décadas más tarde- en su biografía de Vicente Inglés.

La inclusión de la descripción de Javier Fuentes y Ponte en la bibliografía sobre la capilla del Colegio de Teólogos es la principal aportación de este trabajo. Esta fuente es extraordinariamente valiosa, pues Javier Fuentes visitó personalmente y describió con minuciosidad la capilla. Leyéndolo podemos conocer la disposición de los cuadros en los distintos altares laterales a finales del siglo XIX. Una disposición diferente a la que hasta ahora se ha mantenido.

\section{LA AUTORÍA DE VICENTE INGLÉS}

Para la capilla del Colegio de San Isidoro se compuso un ciclo pictórico que la historiografía atribuye al pintor Vicente Inglés, pero lo cierto es que los cuadros no están firmados ni localizados los encargos de las obras de arte que permita afirmarlo de forma inequívoca. También es controvertida la fecha de realización de

12 J. J. Belmonte, Murcia artística, Murcia, 1981. P. Díaz Cassou: Serie de los obispos... 1859. A. Baquero Almansa: Los Profesores... 1913, pp. 280-281.

13 Catálogo de obras restauradas. 1998 a 2007. Memoria del Centro de Conservación y Restauración de Bienes Culturales de la Región de Murcia, Murcia: Dirección General de Bellas Artes y Bienes Culturales, 2008.

14 G. Ruiz Llamas y D. LóPez García: Un programa docente del s. XVIII en Murcia. El pintor Vicente Inglés, Murcia, 2003, p. 46. Con posterioridad, distintos cuadros del ciclo pictórico han participado en distintas exposiciones: El Legado de la pintura, Murcia 1516-1811, Murcia: Ayuntamiento de Murcia 1999, pp. 144-145 (Santa Irene y la Dolorosa); Huellas. Catedral de Murcia. Exposición 2002, pp. 578-579 (la Dolorosa), Lustre y decoro de estos reynos, 2018, (la Dolorosa).

15 J. Fuentes y Ponte: España Mariana. Provincia de Murcia, Lérida: Imprenta Mariana, 188084. Edición de la Fundación Centro de Estudios Históricos e Investigaciones Locales de la Región de Murcia, Murcia, 2005. La redacción de la obra se inició en 1876 y fue terminada en 1880. Se publicó entre 1880 y 1884. La Parte Tercera, que es la que contiene la descripción del Colegio de Teólogos, se publicó en 1882. Biografía y comentario de sus obras en F. ANTÓN HURTADO: «Los forjadores de la Antropología murciana. Javier Fuentes y Ponte», Revista Murciana de Antropología, 2, 1997, pp. 303-314. 
las obras, salvo la del titular, San Isidoro predicando desde la cátedra, que sabemos que ya se encontraba en la capilla en 1766, cuando el obispo Rojas firmó el decreto de erección. ${ }^{16}$ Podemos deducir que el resto del ciclo pictórico se compuso en las años 70 y 80 del siglo XVIII; en todo caso, podríamos ubicarlos en la segunda mitad del reinado de Carlos III (1759-1788).

Como hemos señalado, la primera atribución a Vicente Inglés es de 1871 y se encuentra en la Murcia artística de Juan José Belmonte. En su breve biografía del pintor valenciano, Belmonte refiere:

\begin{abstract}
«Es lo cierto que don Vicente Inglés vivió largo tiempo avecindado en esta capital encargado de la única enseñanza de dibujo que entonces existía, que pintó muchas obras, que si bien no es posible determinar hoy con acierto y exactitud cuales sean, todos convienen en que contribuyen al ornato de nuestros establecimientos públicos, como los cuadros de los altares de la capilla del Instituto provincial de segunda enseñanza que se tienen como suyos». ${ }^{17}$
\end{abstract}

Sin embargo, en otro lugar de su obra, asigna estos mismos cuadros a José Muñoz y Frías y, en particular, el cuadro titular de la capilla, San Isidoro predicando: «También se le atribuye el magnífico cuadro del retablo mayor de la capilla del que fue colegio de San Isidoro, hoy Instituto de $2^{\circ}$ Enseñanza de esta capital y los demás que forman sus altares laterales». ${ }^{18}$

Dos décadas más tarde, en 1895, Pedro Díaz Cassou los atribuye de nuevo a Vicente Inglés, aunque manteniendo algunas reservas:

«En 1781 falleció D. José Muñoz Frías, Director de una cátedra de dibujo en dicha Sociedad [Económica de Amigos del País] y autor de muchos y buenos cuadros. Le sucedió el teniente Director D. Vicente Inglés, de cuya mano, y de 1781, son casi todos los que hay en la capilla del hoy Instituto Provincial, antes Colegio de Teólogos de San Isidoro». 19

Consideraciones parecidas encontramos en Andrés Baquero, pues en un texto afirma que los cuadros del antiguo Colegio de San Isidoro «son todos de D. Vicente Inglés», 20 aunque más tarde, en su biografía del pintor valenciano, matiza: «Fuera de dos o tres, los restantes son, sin duda, de una misma mano». ${ }^{21}$ Aquí

16 F. ARNALDOs: «El colegio de teólogos... », 2008, p. 150

17 J. J. Belmonte: Murcia artística, Murcia, 1981, p. 91.

18 Ibidem, p. 81.

19 P. Díaz Cassou: Serie de los obispos de Cartagena, 1859, pp. 210-211.

20 A. Baquero Almansa: Los Profesores..., 1913, p. 185.

21 Ibidem, p. 280. 
Baquero excluye el San Juan Nepomuceno, que es obra de Pérez Truyol, y, quizá, el San Francisco Javier o el cuadro titular.

En cualquier caso, la biografía conocida de Vicente Inglés no es muy amplia. De origen valenciano, era hijo del pintor José Inglés (Valencia, 1718-1786), miembro de la Academia San Carlos de Valencia, de la que llegó a ser director. En su taller se formaría indudablemente su hijo Vicente. Éste vino a Murcia a mediados del siglo XVIII y en la capital murciana desarrolló su trabajo durante aproximadamente veinticinco años.

Por su procedencia valenciana, nuestro artista no se halla en la tradición de la pintura murciana de la primera mitad de siglo, sino que aportaría, en principio, una visión novedosa. Sin embargo, dada su prolongada estancia en Murcia también es indudable que debió influirle el ambiente artístico de la ciudad y, en particular, la obra y soluciones de Francisco Salzillo, con el que llegó a tener una relación próxima. Estilísticamente Vicente Inglés se enmarca en el Barroco tardío. Algunas obras son claramente barrocas, como el San Alejo o el San Isidoro, pero otras presentan una composición sencilla y elegante, como en el caso de la Dolorosa, que enlaza con otro tipo de sensibilidad más reposada.

Los cuadros de la capilla de San Isidoro le proporcionaron una cierta notoriedad como pintor, de tal manera que, a la muerte de Muñoz y Frías, solicitó la plaza que quedó vacante en la Real Sociedad de Amigos del País. El acta de la Sociedad, de fecha 26 de septiembre de 1781, señala que Vicente Inglés y Joaquín Campos fueron nombrados tenientes directores y socios de mérito. Para ello precedió un informe favorable de Francisco Salzillo -que entonces contaba unos 70 años-, que respaldaba dicho nombramiento. ${ }^{22}$

En las actas de la Sociedad se le menciona por última vez en 1783. Según Baquero, Vicente Inglés volvió a Valencia en esa fecha para heredar el estudio de su padre. Falleció en esta ciudad en 1821.23

22 Diario de Murcia, 13 de marzo de 1889: «D. Vicente Inglés. En el acta de dicha Real Sociedad de fecha 26 de Setiembre de 1781 fueron nombrados tenientes directores y socios de mérito los profesores de pintura D. Vicente Inglés y don Joaquín Campos, precedido informe de Salzillo, que juzgó a los dos capaces para desempeñar el cargo que solicitaban». Carta dirigida a Andrés Baquero y firmada por el conde de Roche. Fechada el 10 de marzo de 1889. Sobre la obra de Vicente Inglés en Murcia, G. Ruiz Llamas y D. López García: Un programa docente..., 2003, pp. 113-131.

23 A. Baquero Almansa: Los Profesores...,1913, p. 281. A. Iborra: «Pintura del siglo XVIII en Murcia», en El Legado de la pintura, Murcia 1516-1811, 1999, pp. 60-63. 


\section{LA DESCRIPCIÓN DE LA CAPILLA POR JAVIER FUENTES Y PONTE (1882)}

La disposición de los cuadros en la capilla del Colegio de San Isidoro fue concebida en el siglo XVIII de acuerdo con un planteamiento teológico que las distintas reformas y traslados de los siglos XIX y XX han hecho desaparecer. La conversión de la capilla en el salón de actos del Instituto Provincial y, finalmente, el traslado de los cuadros a la nueva sede del Instituto Alfonso X el Sabio y al MUSAX sólo nos permite la reconstrucción virtual del ciclo pictórico dieciochesco.

Para una lectura coherente de la disposición de los cuadros nos tenemos que acoger a la descripción de Javier Fuentes y Ponte, el único autor que vio los cuadros en su ubicación original -salvo por el cambio del altar mayor, como veremos- y llevó a cabo una descripción detallada. ${ }^{24}$
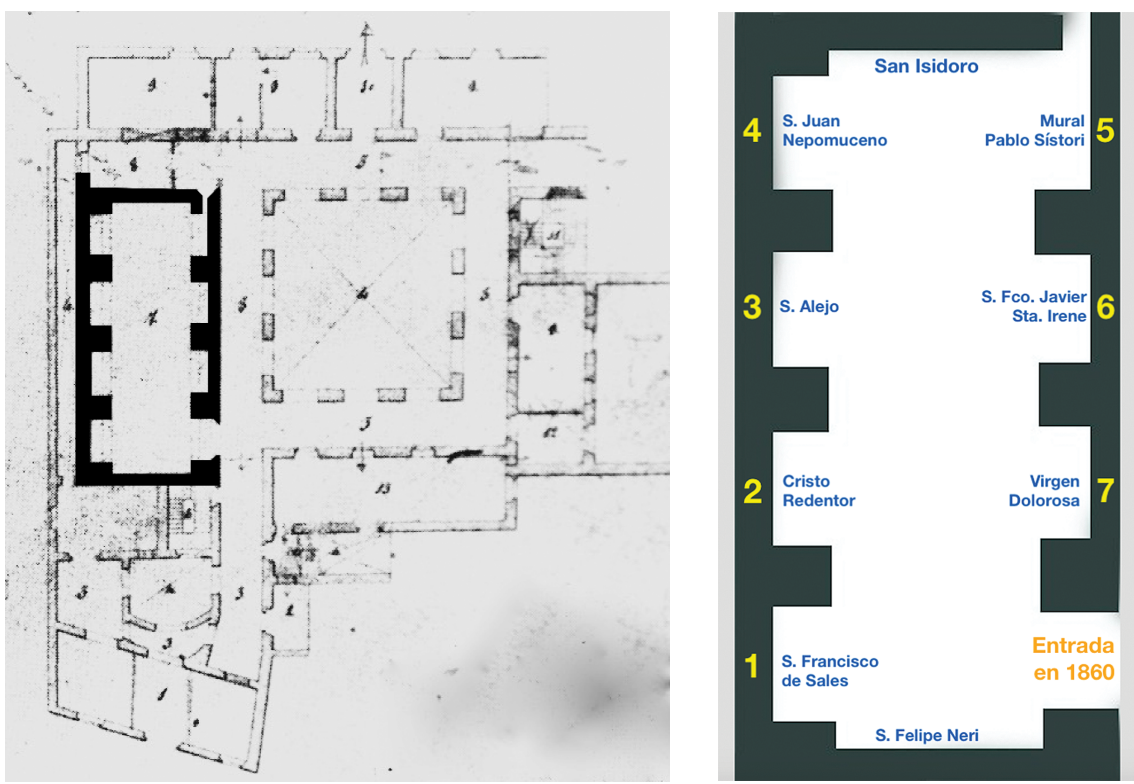

Figura 3. Capilla del Colegio de Teólogos. Disposición de las pinturas según la visita de Javier Fuentes y Ponte. Los números corresponden a su identificación de las capillas laterales. Nótese que en los planos de Guirao la parte superior de la figura es el sur y la inferior el norte.

«La Capilla es una sola nave con cuatro pilastras y cuatro huecos capellares a cada lado, guarnecidos por arcos de medio punto, coronando la decoración, que es de gusto de la época de Luis XV, una cornisa general» (Fuentes y Ponte).

24 Otra explicación del ciclo pictórico, que no se corresponde con la que refiere Fuentes y Ponte, en G. Ruiz Llamas y D. López García: Un programa docente..., 2003, p. 52. 
La Capilla del Colegio de Teólogos es de nave única y presenta ocho capillas o altares laterales. Siguiendo un criterio sencillo y sistemático, Javier Fuentes y Ponte publicó en la tercera parte de su España mariana. Provincia de Murcia (1882) la visita que debió de realizar algún tiempo antes. Esta descripción es la única que se conserva sobre el ciclo pictórico. La descripción y numeración de las capillas-altares que realizó Fuentes y Ponte comienza por los pies de la nave, en el lado del Evangelio y las denomina Primera, Segunda, Tercera y Cuarta capillas; las del lado de la Epístola, comenzando por la cabecera son Quinta, Sexta, Séptima y Octava (Figura 3).

En este trabajo no seguimos ese orden, sino que describimos las parejas de altares desde los pies a la cabecera de la nave, de acuerdo con la concepción del ciclo pictórico: dos santos de los siglos XVI-XVII (Francisco de Sales y Felipe Neri), la Dolorosa y Cristo Resucitado en el centro de la nave, y otros dos santos del mundo antiguo (Irene y Alejo). Queda por discutir el cambio del altar mayor y, por lo tanto, del cuadro titular San Isidoro predicando del testero norte al sur y, en consecuencia, el orden seguido por el ciclo pictórico originalmente.

\section{Capilla lateral 1: San Francisco de Sales}

La Primera Capilla en la descripción de Fuentes es la situada frente a la puerta de entrada que comunica la nave con el claustro. En ella se hallaba un cuadro representando a San Francisco de Sales (1567-1662), obispo de Ginebra. Fuentes y Ponte describe perfectamente la ubicación y el cuadro, aunque lo identifica erróneamente con San Andrés Corsino. 25

\footnotetext{
Esta capilla - dice Fuentes- «es la que, debajo del coro, hace frente a la actual puerta de entrada. Es la primera empezado a contar de izquierda a derecha, costumbre que venimos siguiendo al hacer las descripciones. Tiene una mesa de altar con dos gradas, y sobre ella un cuadro de $1 \mathrm{~m} .28$ de altura por $0 \mathrm{~m} .96$ de ancho ( $\mathrm{sic}$ ), representando al parecer a San Andrés Corsino ( $\mathrm{sic}$ ), de pie, ante una mesa: delante del santo se ve a un niño ángel, sobre cuya cabeza tiene un libro donde escribe aquél en el momento de ser inspirado por el Espíritu Santo, que baja entre ráfagas y cuatro querubines». ${ }^{26}$
}

25 Andrés Corsini, 1302-1373, carmelita italiano, obispo de Fiésole, canonizado en 1665. Por su parte, en el Catálogo de obras restauradas. 1998 a 2007..., 2008, p. 177, del Centro de Conservación y Restauración de Bienes Culturales, lo nombra como San Carlos Borromeo.

26 J. Fuentes y Ponte, España mariana, 1882, p. 54. 


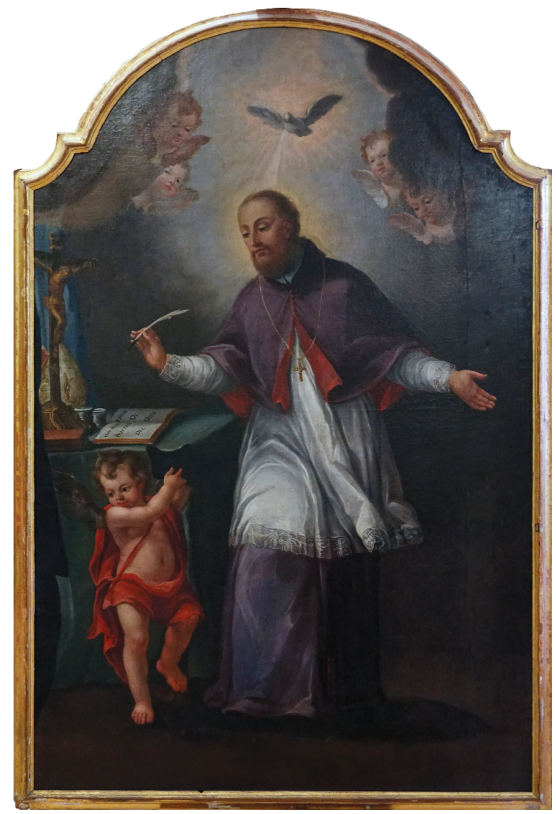

Figura 4. Vicente Inglés. San Francisco de Sales. Oleo sobre lienzo. 185,5 x 121,5 cm

Dimensiones del marco: 194,5 x 130,5 cm.

«De pie, ante una mesa: delante del santo se ve a un niño ángel, sobre cuya cabeza tiene un libro donde escribe aquél en el momento de ser inspirado por el Espíritu Santo, que baja entre ráfagas y cuatro querubines» (Fuentes y Ponte).

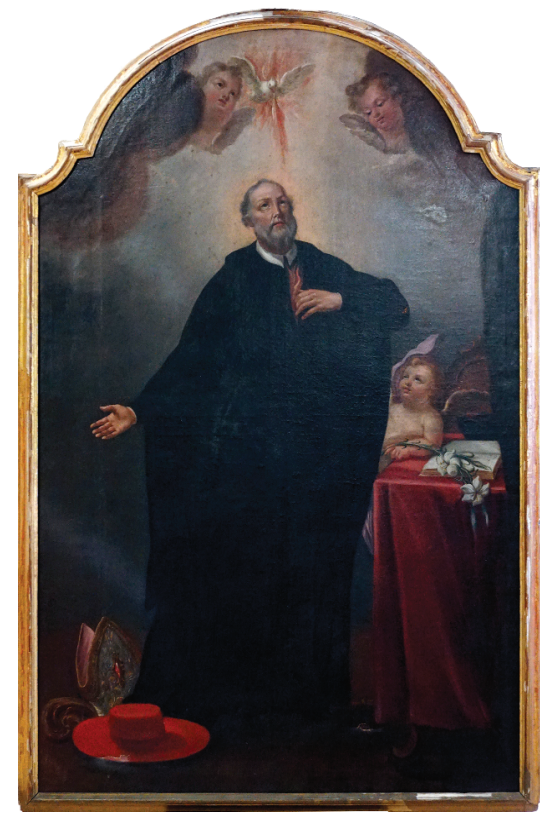

Figura 5. Vicente Inglés. San Felipe Neri. Oleo sobre lienzo. 185,5 x 121,5 cm.

Dimensiones del marco: 194,5 x 130,5 cm.

«Vestido con sotana y manteo, escribiendo junto a una mesa en cuyo lado hay un ángel niño. El Espíritu Santo rodeado de querubines desciende hacia el inspirado escritor» (Fuentes y Ponte).

El santo viste sotana, sobrepelliz blanca y muceta episcopal morada. Su colorido contrasta con el negro del hábito de su compañero San Felipe Neri, con el que forma pareja. Sobre su pecho porta una cruz. La composición esta dominada por la luz que desciende sobre la cabeza del santo y las diagonales que forman sus brazos. Al efecto barroco de los paños contribuye su gesto de adelantar la pierna derecha.

Sobre la mesa hay un crucifijo, un tintero, una mitra y un libro, situado éste sobre la cabeza de un ángel. En sus páginas abiertas podemos leer: Viva Iesus. Práctica del amor de Dios. Y, efectivamente, este título se corresponde con una obra 
de Francisco de Sales, por lo que no puede haber ningún tipo de duda en cuanto a su identificación. El cuadro narra el momento de inspiración mística del santo. ${ }^{27}$

\section{Capilla lateral 2: San Felipe Neri}

La capilla lateral 2 (Capilla Octava de Fuentes) se ubicaba en el espacio que, desde la reforma de Ángel Guirao, ocupaba la puerta de entrada a la nave, es decir, la primera capilla del lado de la Epístola. Al abrirse aquí, en la reforma citada, la nueva puerta de entrada a la nave, el cuadro y el altar hubieron de ser desplazados al muro de fondo, justo donde estaba la antigua puerta de entrada, tapiada entonces.

«En el lado E de dicho claustro se halla la nueva puerta de la Capilla, rasgada al efecto, inutilizando el primer altar del lado derecho; cuya mesa de altar y cuadro están hoy colocadas en la pared que se ha hecho a los pies de la capilla, cerrando su antigua entrada bajo el coro».28

El cuadro representa a San Felipe Neri, sacerdote italiano del siglo XVI, que vivió en Roma y fue canonizado en 1622. No obstante, Fuentes y Ponte no menciona en ningún momento el nombre de Felipe Neri, a pesar de ser una devoción muy arraigada en Murcia, pues había sido promovida por el obispo Belluga, que instaló una casa en la ciudad, como recuerda Díaz Cassou. ${ }^{29}$

Fuentes en realidad confunde este cuadro con su pareja de la capilla lateral 1. Se refiere a él como San Francisco de Sales y también trastoca una parte de la descripción -menciona cuatro querubines en lugar de dos-, posiblemente por una confusión en sus notas o a la hora de redactar, quizá debida a la similitud compositiva de los dos cuadros. Sin embargo, esta confusión se ha repetido en la historiografía, pues se encuentra en Los profesores de las Bellas Artes murcianos de

27 Practica del amor de Dios que en francés escribió San Francisco de Sales, Obispo, y Príncipe de Geneva, fundador de la Orden de la visitación de Santa María. Traduxo al castellano el Licenciado D. Francisco Cuvillas Donyague, presbitero, abogado de los Reales Consejos. Con un epitome de la vida del mismo santo, Madrid, 1768: «Día de la Anunciación de Nuestra Señora, recogido por la siesta a rezar el Rosario, como solía, se puso después delante de un Santo Christo, a meditar un capítulo que empezaba, quando a poco rato baxó el Espíritu Santo sobre él visiblemente, en un globo de fuego, que se dividió en muchas llamas, cubriéndole por todas partes».

28 J. Fuentes y Ponte: España mariana, 1882, pp. 53-54.

29 P. Díaz Cassou: Serie de los obispos de Cartagena, 1859, p. 168: «En Murcia hizo casa y huerto para instalar (7 Abril 1713) aquellos Felipenses o Padres del Oratorio que había traído en 1706, y a quienes siempre fue tan aficionado». F. ARnAldos: «El Colegio de Teólogos...», 2008, p. 144. Felipe Neri (Florencia 1515-Roma 1595) fundó la Congregación del Oratorio en Roma en 1575. 
Andrés Baquero, que en esto sigue a Fuentes y Ponte. ${ }^{30}$ La imagen fue correctamente identificada por Gracia Ruiz Llamas y David López en su estudio de la obra de Vicente Inglés. 31

\begin{abstract}
«El cuadro - escribe Fuentes- es de $1 \mathrm{~m} .28$ de altura por $0 \mathrm{~m} .96$ de ancho (sic), representando a San Francisco de Sales (sic), vestido con sotana y manteo, escribiendo junto a una mesa en cuyo lado hay un ángel niño. El Espíritu Santo rodeado de cuatro (sic) querubines desciende hacia el inspirado escritor». ${ }^{32}$
\end{abstract}

Como hemos indicado, el lienzo había sido desplazado a los pies de la nave al abrirse la puerta que comunicaba la capilla con el claustro. El hueco de la capilla lateral todavía conservaba restos de las perspectivas fingidas, que contorneaban los cuadros, pintadas en toda la capilla por el muralista Pablo Sistori.

\begin{abstract}
«Ésta es la que hoy sirve de entrada, habiendo pasado su mesa de altar, grada y cuadro al frente de los pies de la nave, que, como indicamos al principio, el frente de este octavo hueco capellar conserva aún algún resto de la pintura mural que hizo D. Pablo Sistori, en ella; como también, más o menos mutilados y mal restaurados, consérvanse los otros frescos en todos los ya descritos huecos capellares, cuyos muros están pintados por tan insigne artista, figurando pórticos de varios ordenes arquitectónicos o guarniciones de cartonaje para contornar los cuadros al óleo». ${ }^{33}$
\end{abstract}

Felipe Neri aparece representado en un momento de inspiración. El Espíritu Santo, flanqueado por dos querubines, desciende sobre él. De pie, viste el hábito filipense de color negro, muy amplio, lo que da al lienzo la mayor simplicidad compositiva del conjunto. Lleva su mano izquierda al corazón, de la que surge una llama, uno de los dones del santo. Según su biografía oficial, por primera vez en la víspera de Pentecostés de 1544, entregado a la oración y en estado de éxtasis fue poseído por un globo de fuego que dilató su corazón.

A la izquierda del santo figura una mesa y en ella un ángel, que le observa. Un libro y una azucena completan el conjunto. En la parte inferior del cuadro aparecen una mitra, un báculo y un capelo cardenalicio. Esto elementos, situados a los pies del

30 A. Baquero Almansa: Los profesores..., 1913, p. 281. Baquero menciona a San Andrés Corsino pero no a San Felipe Neri ni a San Francisco de Sales.

31 G. Ruiz Llamas y D. López García: Un programa docente del s. XVIII en Murcia, 2003, pp. 82-87. Por su parte, en el Catálogo de obras restauradas. 1998 a 2007..., 2008, p. 177, del Centro de Conservación y Restauración de Bienes Culturales, lo nombra como San Francisco de Sales.

32 J. Fuentes y Ponte, España mariana, 1882, p. 54. El texto confunde el nombre del personaje representado, en realidad San Felipe Neri, y el número de querubines que rodean al Espíritu Santo, dos en lugar de cuatro.

33 J. Fuentes y Ponte, España mariana, 1882, p. 56. 
personaje, trasmiten un mensaje de sencillez y humildad, aluden a su labor de confesión de estas dignidades eclesiásticas que Felipe Neri, simple sacerdote, no quiso para sí. La presencia de estos elementos, propios de una dignidad eclesiástica más encumbrada, también han podido conducir a la confusión a la que nos hemos referido.

San Felipe Neri, San Francisco de Sales y San Isidoro aparecen como santos inspirados por el Espíritu. Con ellos se transmiten a los colegiales un mensaje didáctico, la difusión de la palabra por medio de la predicación y la escritura.

\section{Capilla lateral 3. Cristo Redentor}

En los altares centrales de la nave se situaban, frente a frente, las imágenes de Cristo resucitado y de la Virgen Dolorosa. El primero es descrito brevemente por Fuentes:

«Sobre la mesa de altar hay una grada y un cuadro $1 \mathrm{~m} .28$ de altura por $0 \mathrm{~m} .83$ de ancho (sic), paisaje de dilatado horizonte y, en primer término, Jesús adelantándose, de frente, con los brazos abiertos, en cuyas manos, así como en los pies, vense las sacrosantas llagas. Sobre su cabeza hay cuatro querubines». 34

El cuadro presenta la composición más sencilla del ciclo. El tema es el de Cristo Redentor de la humanidad (Redemptor hominis). Un Jesús resucitado, con los brazos abiertos, que no responde estrictamente a un estilo barroco genuino, incluso cabría decir que enlaza con la sensibilidad del espectador actual. Jesús aparece rodeado de una aureola de luz que centra la mirada en su rostro. De pie, ocupa el centro de la composición, formando, con sus brazos abiertos, una especie de mandorla. El cuerpo está elegantemente compuesto, con la pierna derecha adelantada. Su rostro, de cabello largo y barbado, es dulce y sereno, quizá algo inexpresivo. Viste túnica morada y un manto azul oscuro. Cuatro querubines entre nubes forman un arco en el cielo y son testigos de esta epifanía.

En segundo plano se dibuja un paisaje sin gran detalle y sin ninguna figura humana, que podría ser una imagen de la creación prístina. El colorido presenta tonalidades suaves.

\section{Capilla lateral 4. Virgen Dolorosa}

Enfrente de Jesús, la imagen de la Virgen de los Dolores, concebida al atardecer, en una especie de crepúsculo simbólico que manifiesta la muerte de Cristo. La composición esta dominada por dos diagonales: una formada por la luz y otra

34 J. Fuentes y Ponte: España Mariana, 1882, p. 54. Para Fuentes es la Segunda Capilla. 


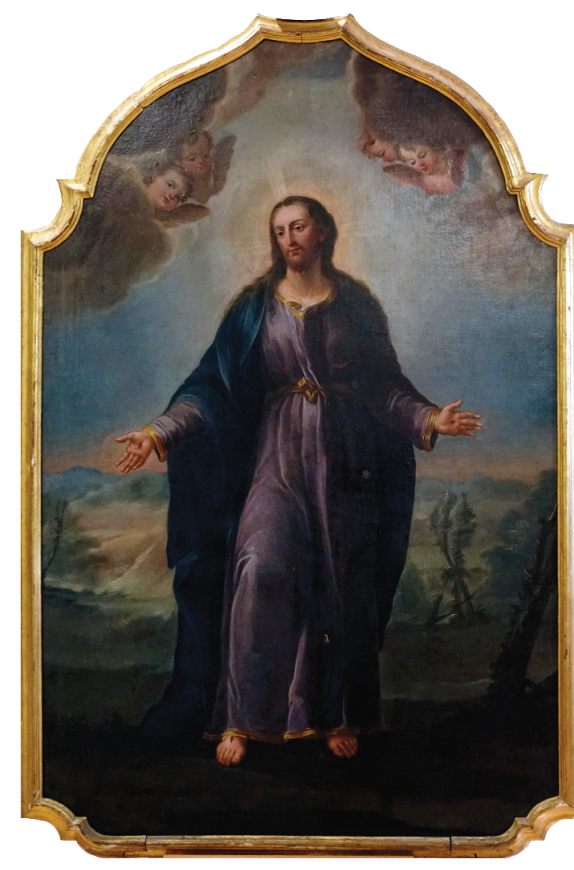

Figura 6. Vicente Inglés. Cristo Redentor. Oleo sobre lienzo. 184 x $118 \mathrm{~cm}$.

Dimensiones del marco: $193 \times 127,5 \mathrm{~cm}$.

«Paisaje de dilatado horizonte y, en primer término, Jesús adelantándose, de frente, con los brazos abiertos, en cuyas manos, así como en los pies, vense las sacrosantas llagas. Sobre su cabeza hay cuatro querubines» (Fuentes y Ponte).

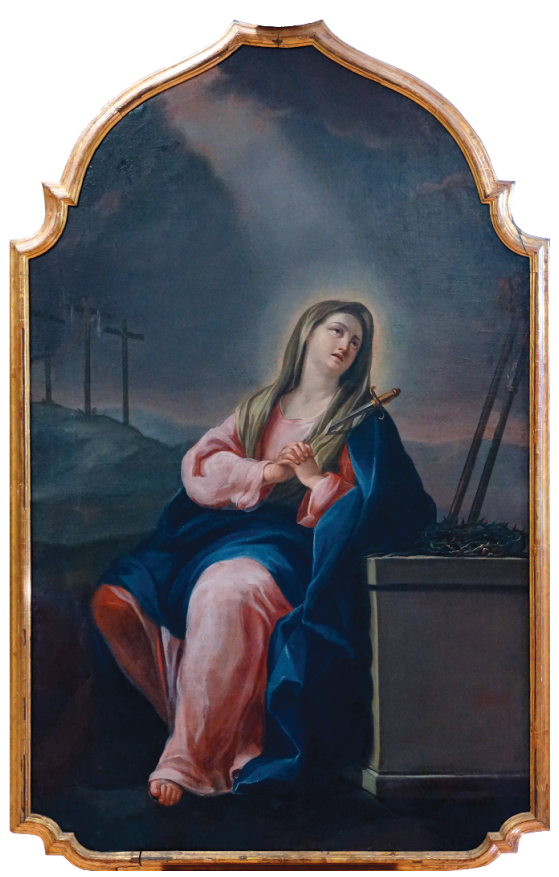

Figura 7. Vicente Inglés. Virgen Dolorosa. Oleo sobre lienzo. 184 x $118 \mathrm{~cm}$.

Dimensiones del marco: 194 x 127,5 cm.

«Se la ve sentada junto a un pedestal en que hay agrupados los instrumentos accesorios de la pasión, la corona, los clavos, la lanza y la esponja; descubriéndose en el fondo del paisaje el calvario con las tres cruces. La triste Madre tiene atravesado su pecho con el cuchillo de su dolor, oprimiendo contra él sus cruzadas manos: alza su mirada al cielo y tiene túnica de color de rosa con manto azul» (Fuentes y Ponte).

dibujada por el cuerpo de María y los emblemas de la Pasión. Aparece vestida con los colores habituales: una túnica roja, una manto azul y un velo amarillo verdoso que le cube la cabeza.

«Tiene una mesa de altar y una grada del mismo género que las otras indicadas, sobre ella está el cuadro en lienzo de $1 \mathrm{~m} .32$ de altura por 0.93 de ancho (sic), la Virgen Dolorosa, a 
la cual se la ve sentada junto a un pedestal en que hay agrupados los instrumentos accesorios de la pasión, la corona, los clavos, la lanza y la esponja; descubriéndose en el fondo del paisaje el calvario con las tres cruces. La triste Madre tiene atravesado su pecho con el cuchillo de su dolor, oprimiendo contra él sus cruzadas manos: alza su mirada al cielo y tiene túnica de color de rosa con manto azul». ${ }^{35}$

Un puñal clavado en el corazón representa la muerte de su Hijo y la señala como Mater Dolorosa. Con lágrimas en los ojos, cruza las manos y mira al cielo. Su mirada hacia arriba corresponde a la iconografía de la Dolorosa. No obstante, el tiempo elegido es presumiblemente la última hora del Viernes -o la tarde de Sábado Santo- pues la cruz aparece vacía y a un lado los instrumentos de la Pasión; en este sentido, también representa la Soledad de María. Sin patetismo, con expresión serena, su dolor es reflexivo y esperanzado.

Sobre el cuadro - comenta Fuentes y Ponte- se conservaba una inscripción pintada alusiva al tema, cuya fuente son las Lamentaciones de Jeremías: «Posuit me desolatam, tota die moerore confectam». 36

La composición es sencilla, de tono popular y estética tardobarroca. Muy próxima a la sensibilidad de las imágenes de Salzillo. ${ }^{37}$

\section{Capilla lateral 5. Tránsito de San Alejo}

En la capilla lateral 5, situada en el lado del Evangelio según la descripción de Fuentes y Ponte, aparece la representación del Tránsito de San Alejo, un santo de origen oriental, cuya leyenda se remonta al siglo V. Fuentes y Ponte describe el altar y el cuadro:

«La mesa de celebración es, como todas las demás, del gusto artístico de la época de la capilla, y sobre ella están dos gradas, encima de las cuales álzase un cuadro de $1 \mathrm{~m} .36$ de altura por 0m.97 de ancho ( $\mathrm{sic}$ ), representado el dichoso tránsito de San Alejo: el santo está espirante debajo de la escalera, teniendo una tablilla en la mano izquierda y un libro abierto en la derecha. Dos ángeles niños desciende trayendo el uno un escudo con el nombre del santo y el otro un báculo de caminante. En la parte superior se ven cuatro querubines en una ráfaga». ${ }^{38}$

35 J. Fuentes y Ponte: España mariana, 1882, p. 56. Para Fuentes es la Capilla Séptima. Este cuadro ha sido expuesto en El legado de la pintura, 1999, p. 145, en Huellas, 2002, pp. 578-579, y en la exposición Lustre y decoro de estos reynos, promovida por La Academia de Bellas Artes de Santa María de la Arrixaca y el Ayuntamiento de Murcia (2018), en la que aparece titulada como Soledad.

36 Lam. 1, 13: Me ha dejado desolada, para siempre dolorida.

37 J. A. Miravete: El antiguo Colegio de Teólogos de San Isidoro, Murcia, 2017, p. 24.

38 J. Fuentes y Ponte, España mariana, 1882, p. 54. Para Fuentes es la tercera capilla. 

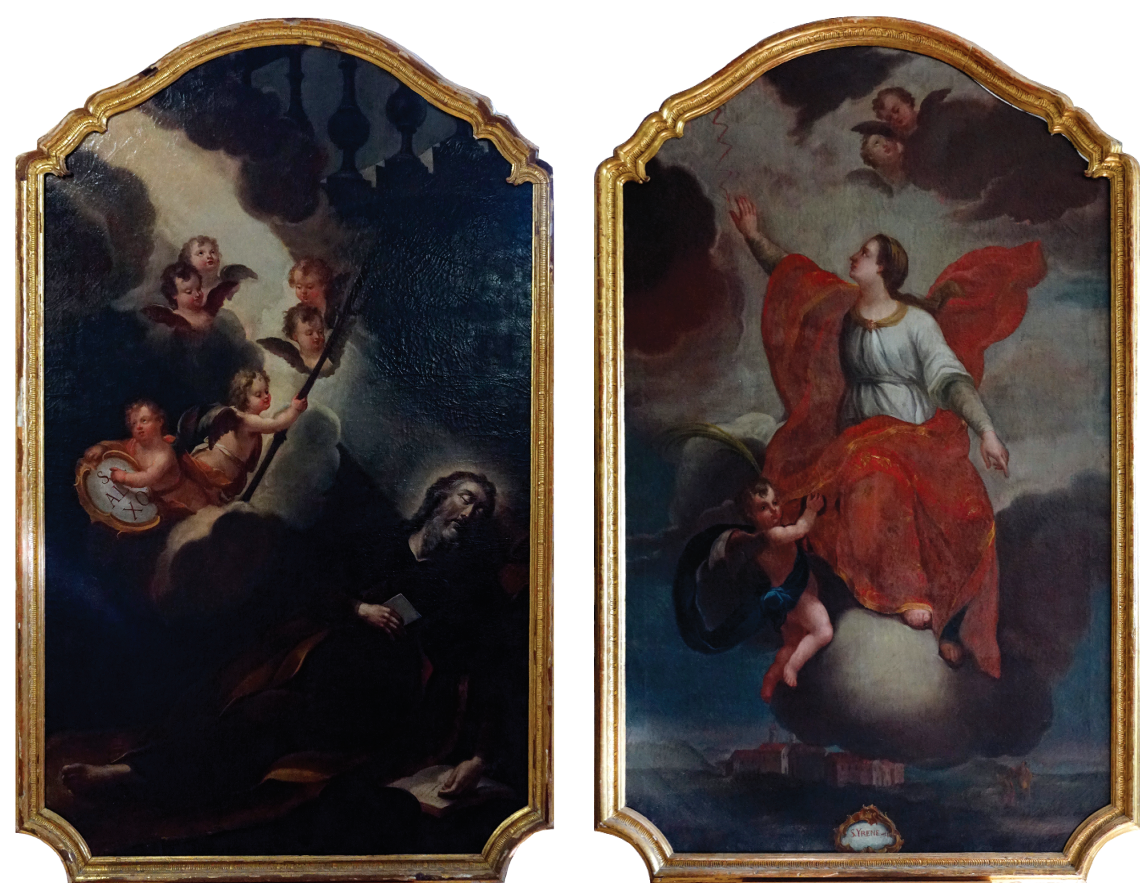

Figura 8. Vicente Inglés. Tránsito de San Alejo. Oleo sobre lienzo. 178,5 x $109 \mathrm{~cm}$.

Dimensiones del marco: 190,5 x $122 \mathrm{~cm}$.

«El santo está espirante debajo de la escalera, teniendo una tablilla en la mano izquierda y un libro abierto en la derecha. Dos ángeles niños desciende trayendo el uno un escudo con el nombre del santo y el otro un báculo de caminante. En la parte superior se ven cuatro querubines en una ráfaga» (Fuentes y Ponte).

Figura 9. Vicente Inglés. Santa Irene. Oleo sobre lienzo. 178,5 x $109 \mathrm{~cm}$.

Dimensiones del marco: 190,5 x $122 \mathrm{~cm}$.

«En la parte inferior se extiende un paisaje con una ciudad y dos figuras orando hacia el cielo. Sobre una nube va sentada Santa Irene, y a su lado un ángel niño sosteniendo la palma del martirio: La Santa, extendiendo con interés suplicante el brazo derecho, parece detener una centella que desde unas negras nubes despréndese hacia la ciudad. Sobre la cabeza de la mártir, abogada contra el fuego del cielo, dos querubines» (Fuentes y Ponte). 
De técnica tenebrista, es el cuadro más barroco de la serie. La escena aparece dominada por un haz de luz diagonal que, procedente del ángulo superior izquierdo del espectador, ilumina la cara del santo. La composición se contrarresta con otra serie de diagonales, en sentido contrario, formadas por ángeles, querubines, el cuerpo del protagonista y su báculo de peregrino.

La leyenda de San Alejo refiere que, nacido en una familia de patricios romanos y después de una vida de eremita, murió bajo la escalera de su casa, representada por cinco balaustres en penumbra, situados en la parte superior del lienzo. Hospedado por caridad en su propia casa, al sentir el anuncio de su muerte, Alejo pidió un pergamino donde anotó su nombre, gracias a lo cual fue reconocido por su padre. Su humildad lo convierte en patrono de la caridad, del sacrificio y de la mortificación de la vida eremítica. Viste pobremente, un sallo de color marrón oscuro. Su cara es la de un anciano barbado, con el cabello largo. Los ojos cerrados representan el momento de la expiración.

De toda la serie, es el que presenta un mayor número de figuras angélicas: cuatro querubines y dos ángeles. Uno lleva un báculo, símbolo del peregrino, y otro una rocalla en la que aparece el nombre del santo: «S./AL(E)/XO»

A los colegiales murcianos, la vida de San Alejo les enseñaba presumiblemente una importante lección: la renuncia a los bienes terrenales e incluso a la propia familia.

\section{Capilla lateral 6. Santa Irene y San Francisco Javier}

Santa Irene. Por la cartela inferior: «S.YRENE» conocemos el nombre de la santa representada en el cuadro; pero, ¿quién es esta Santa Irene? Es la iconografía más extraña del conjunto, pues no encaja ni con la de Tesalónica del siglo IV, ni la de Roma del siglo VI, ni con la de Portugal (Santa Iria), también del VI, que fue arrojada a un río. G. Ruiz Llamas y David López la identifican con esta última: Santa Irene de Tancor, una mártir portuguesa de época visigoda nacida en Nabancia o Tomar. ${ }^{39}$ La razón por la que se habría incluido en el ciclo pictórico sería como modelo de castidad: virgen y mártir. Fuentes y Ponte describe el cuadro y la capilla en la que se ubica:

«Como en todas las demás hay una mesa de celebración con grada, y en esta se ve un Sagrario muy pequeño; sobre ella se alza un cuadro de $1 \mathrm{~m} .28$ de altura por $0 \mathrm{~m} .96$ de ancho (sic): en la parte inferior se extiende un paisaje con una ciudad y dos figuras orando hacia el cielo. Sobre una nube va sentada Santa Irene, y a su lado un ángel niño soste-

39 G. Ruiz Llamas y D. LóPez García: Un programa docente..., 2003, pp. 93-97. Este cuadro ha sido expuesto en El Legado de la pintura..., 1999, p. 144. 
niendo la palma del martirio: La Santa, extendiendo con interés suplicante el brazo derecho, parece detener una centella que desde unas negras nubes despréndese hacia la ciudad. Sobre la cabeza de la mártir, abogada contra el fuego del cielo, dos querubines». ${ }^{40}$

La escena aparece dividida en tres partes. La superior, el mudo celestial; la central compuesta por la imagen de la santa apoyada en una nube, junto con un ángel que porta la palma del martirio; $\mathrm{y}$, la inferior, el mundo terrestre. Su cuerpo traza una diagonal y, con sus brazos, parece unir la parte superior e inferior, interpretando el papel de mediadora. Viste túnica blanca y manto rojo, éste se encuentra desplegado, en vuelo, en apariencia de un ala, lo que le da ligereza a la figura. Dos querubines entre nubes y un rayo zigzaguea hasta el dedo índice de su mano derecha. Sus manos parecen canalizar esta fuerza divina del cielo a la tierra.

En la parte inferior del cuadro se muestra una localidad en penumbra, en tonos marrón y ocre. Puede estar referida a Santarem, es decir, a la villa de Escalabis, que cambió su nombre, adoptando el nombre de la santa. En ella aparecen unas figuras humanas que, de aceptar su identificación con la santa portuguesa, serían los que descubrieron su cuerpo arrojado al el río Naban. No obstante, subsiste el misterio de la protagonista. De acuerdo con nuestra propuesta se trata de una santa del mundo antiguo, paralela a San Alejo, aunque desconocemos el origen de esta devoción en la ciudad de Murcia y la razón exacta por la que fue elegida Santa Irene.

Fuentes no aporta otra información sobre este punto, pero sí sobre el resto de esta capilla lateral; en primer lugar, sobre las inscripciones pintadas que había a ambos lados del altar y que son los que siguen:

-Lado izquierdo: «Altar privilegiado en los lunes y viernes y octava de difuntos».

-Lado derecho: «El Ilmo. Sr. Obispo de Cartagena concedió cuarenta días de indulgencia a quien rece un Padrenuestro y un Ave María delante de esta santa imagen de Santa Irene». ${ }^{41}$

Pero lo más novedoso de esta capilla lateral es lo siguiente. Sobre el cuadro de Santa Irene había otra imagen representando a San Francisco Javier, que también conservamos. Esta información es preciosa porque pone en cuestión la explicación tradicional que se ha dado sobre la ubicación de este último cuadro.

San Francisco Javier. La información ofrecida por Fuentes nos permite afirmar que la imagen de San Francisco Javier estaba situada originalmente sobre el cuadro de Santa Irene, integradas ambas obras en la arquitectura fingida diseñada por Pablo Sistori.

40 J. Fuentes y Ponte: España mariana, 1882, pp. 55-56. Para Fuentes es la Capilla Sexta.

41 Ibídem 


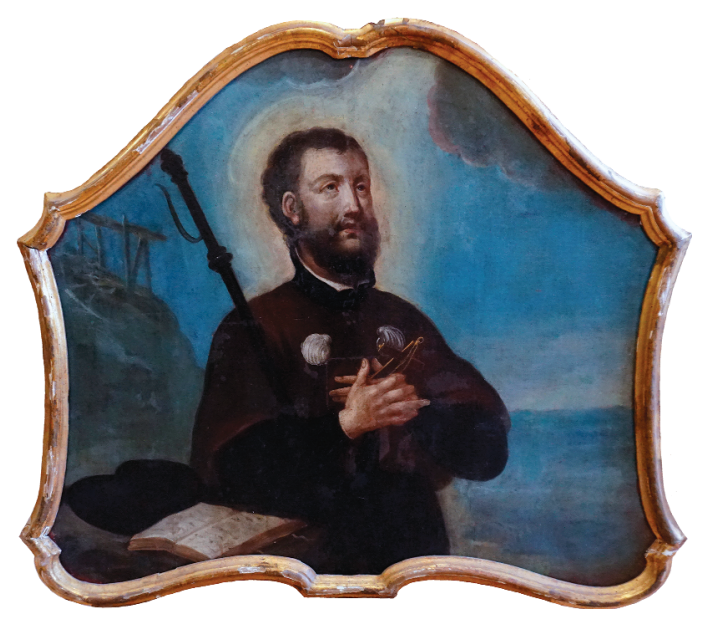

Figura 10. Vicente Inglés. San Francisco Javier.

Oleo sobre tabla. $61,5 \times 74,5 \mathrm{~cm}$.

Dimensiones del marco: $65 \times 80 \mathrm{~cm}$.

«Sobre el cuadro de la santa e imitando copete de la pintada decoración mural, hay un cuadro en lienzo (sic) de $0.60 \mathrm{~m}$ de ancho por 0.45 de altura ( sic), media figura San Francisco Javier vestido de peregrino, apretando sus dos manos contra el pecho». 42

Por lo tanto, este cuadro, que posteriormente estuvo situado sobre la puerta de la capilla abierta durante la reforma de 1866, no fue pensado, como se ha interpretado en ocasiones, para ser visto a la salida de la nave y enviar así un último mensaje a los colegiales: el camino de la evangelización y de las misiones, del que es patrono el santo navarro. Igualmente, habría otra cuestión a tener en cuenta, es el hecho de que se trate de un santo jesuita, porque recordamos que la Orden fue expulsada por Carlos III en 1767, tres meses después de la inauguración del Colegio.

Se trata de una composición sencilla pues su colocación en altura no exigía excesivos detalles. El santo aparece de medio cuerpo, vestido con hábito de peregrino, con dos conchas santiaguistas en él y las manos cruzadas sobre el pecho, portando una cruz, lo que, tal vez, puede ser una alusión a un episodio de legendario de su biografía. Tras él, un bordón alude a su misión de peregrino. A su derecha un sombrero y un libro abierto (¿Los Ejercicios Espirituales de san Ignacio

42 Ibídem, p. 56. 
de Loyola?). El mar nos informa de sus viajes a Oriente. En el fondo del cuadro, a sus espaldas, se descubre una especie de calvario, similar al de la Virgen de los Dolores, una alusión probable al martirio de sus compañeros en Japón.

De todo el ciclo, es el único cuadro pintado sobre tabla.

\title{
Capillas laterales 7 y 8. San Juan Nepomuceno
}

Estas dos capillas (Cuarta y Quinta de la numeración de Fuentes) están situadas justo a ambos lados del altar mayor. No acogían ningún cuadro de Vicente Inglés, sino un lienzo, de menor tamaño, que no formaba parte del ciclo iconográfico y es obra del pintor murciano José Antonio Pérez Truyol, llamado el Mudo. Este cuadro se hallaba en el lado del Evangelio, mientras que únicamente restos de las pinturas murales de Paolo Sistori se situaban enfrente, en el lado de la Epístola.

Sobre la capilla de San Juan Nepomuceno, de nuevo la descripción de Fuentes es sucinta:

\begin{abstract}
«No tiene mesa de altar y sólo sirve de paso a lo que fue sacristía (sic). En su frente hay un cuadro en lienzo de muy escaso mérito, que tiene $0 . \mathrm{m} 74$ de altura por $0 \mathrm{~m} .70$ de ancho (sic), San Juan Nepomuceno, cuya figura está arrodillada en una nube, entre dos niños ángeles y cuatro querubines».
\end{abstract}

$\mathrm{Y}$, respecto a la siguiente capilla, señala:

«Ésta, siguiendo el orden, es la primera de la izquierda bajando del altar mayor: hace frente con la cuarta, en que hemos marcado que está el cuadro de San Juan Nepomuceno; pero en esta no hay en su frente más que una puerta de dos hojas, admirablemente figurada en perspectiva mural por el famoso fresquista Sistori»». ${ }^{43}$

La descripción de Fuentes trastoca el orden de las capillas, pues, según los planos mandados levantar por Ángel Guirao, el paso a la llamada antigua sacristía se realizaba por el lado de la Epístola.

En cuanto al cuadro, durante algún tiempo se ha considerado que pudiera estar destinado originalmente a la sacristía, pues no forma parte del ciclo pictórico. Sin embargo, también es razonable su ubicación en la capilla lateral 7, en la que podría haber estado originalmente un confesionario.

El santo porta un crucifijo, una azucena y la palma del martirio. Un ángel a sus pies muestra la corona, y otro, a su izquierda, un libro y unas llaves. Este últi-

43 J. Fuentes y PONTE: España mariana, 1882, pp. 54-55. 


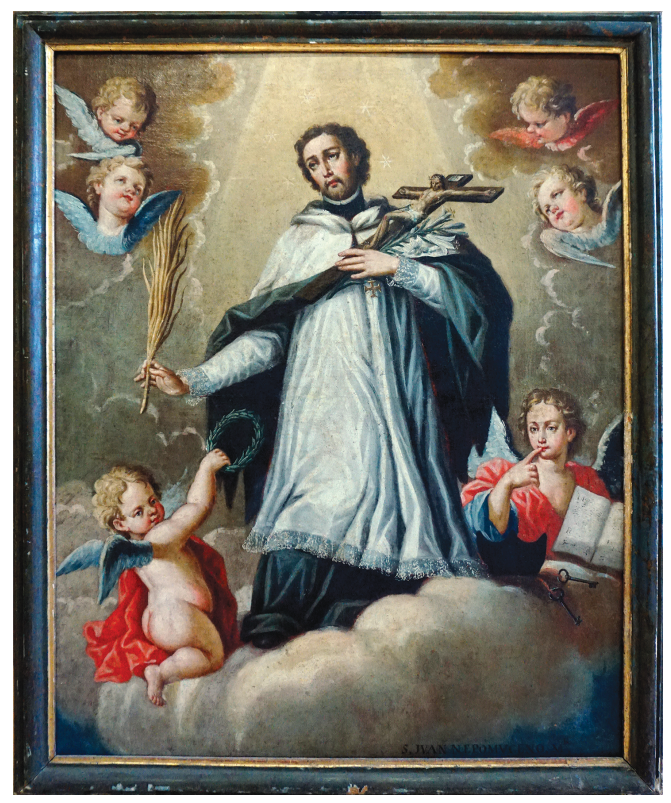

Figura 11. José Antonio Pérez Truyol. San Juan Nepomuceno. Oleo sobre lienzo. 106,5 x 88,5 cm.

Dimensiones del marco: 121 x $99 \mathrm{~cm}$.

«San Juan Nepomuceno, cuya figura está arrodillada en una nube, entre dos niños ángeles y cuatro querubines» (Fuentes y Ponte).

mo tiene el índice de su mano derecha sobre sus labios, aludiendo al secreto de la confesión, causa del martirio del santo checo, canonizado en 1729.44 Su nombre aparece en un epígrafe a los pies del cuadro.

El autor es José Antonio Pérez Truyol, el Mudo. Un autor en la estela local de Senén Vila y del que escribe Andrés Baquero: «Sus obras no carecen de mérito, considerándolas como intentos gallardos de un aficionado con aptitudes». Asimismo, la atribución de autoría se debe al erudito murciano:

44 San Juan Nepomuceno (1340-1393). Presbítero. Patrono de Bohemia y de la Infantería de Marina española. Sufrió martirio por guardar el secreto de la confesión. Murió arrojado al río Moldava en Praga. 
«En la Capilla del antiguo Colegio de San Isidoro (hoy Instituto Provincial) se distingue de los demás cuadros, que son todos de D. Vicente Inglés, uno de tamaño "pousinesco" y muy diferente factura, que representa a San Juan Nepomuceno. Aunque no lleva firma, es, parece, del "Mudo" murciano». ${ }^{45}$

Por otra parte, la capilla situada enfrente no incluía ningún cuadro, sino únicamente las pinturas murales de Pablo Sistori. De origen napolitano, Sistori se estableció en Murcia en el último tercio del siglo XVIII. Trabajó, como hemos visto, en todos los altares de la capilla del Colegio y ha sido calificado como pintor de perspectivas fingidas. ${ }^{46} \mathrm{Su}$ obra en el Colegio de Teólogos se ha perdido.

\section{EL ALTAR MAYOR DEL COLEGIO DE SAN ISIDORO}

\section{La ubicación primitiva del altar mayor}

Como hemos señalado anteriormente, la descripción del ciclo pictórico que realiza Javier Fuentes y Ponte no coincide con el publicado en 2003 por Gracia Ruiz Llamas y David López. ${ }^{47}$ Pero, además, hay un nuevo argumento que cambiaría el sentido del programa educativo elaborado en el siglo XVIII para los colegiales de San Isidoro. Es la consideración de que el altar mayor de la capilla del Colegio y, en consecuencia, el cuadro titular: San Isidoro predicando desde la cátedra, no estaría situado originalmente en el testero sur de la nave, sino en el lado norte, y que fue presumiblemente en la reforma de Ángel Guirao cuando se cambió esta disposición.

Sin duda, esta hipótesis daría otro sentido al programa iconográfico. Si consideramos el muro norte como la ubicación original del altar mayor, San Alejo y Santa Irene se hallarían en las capillas laterales más alejadas; Jesús y la Virgen en el centro de la nave y del programa docente; y San Felipe Neri y San Francisco de Sales estarían situados en las capillas laterales dispuestas justo a ambos lados del altar mayor. Y lo cierto es que este programa también es un relato didáctico cohe-

45 A. BAQUeRO: Los profesores..., 1913, p. 185.

46 Ibidem, p. 271. Lo califica de «habilísimo pintor de perspectivas, al freso y al temple».

47 G. Ruiz Llamas y D. LóPez García: Un programa docente..., 2003, p. 52. Según estos autores habría un in crescendo del mensaje religioso de las parejas de cuadros conforme nos acercamos desde los pies de la nave al altar mayor: San Alejo y Santa Irene representan modelos prácticos y ejemplos de vida; San Francisco de Sales y San Felipe Neri, como santos clérigos, representan dos modelos instructivos o de formación de los colegiales; y, por último, la Virgen y Jesús serían modelos divinos en la tierra y, por ello, irían situados a ambos lados del altar mayor. Finalmente, San Isidoro en el centro, modelo de la institución. 
rente para la formación de los colegiales, pues colocaría en primer plano a dos santos más próximos en el tiempo y, en los pies, a aquellos más alejados cronológicamente. Pero, además, si consideramos este cambio de cabecera, podemos observar como las parejas de cuadros así dispuestas giran su rostro hacia el testero norte, el que entendemos como altar mayor primitivo.

Para sostener esta propuesta, contamos también con el testimonio de Andrés Baquero, que recoge este dato en su biografía de Pablo Sistori:

«A este éxito [se refiere al Oratorio particular del Palacio del Obispo] seguiría el de la capilla del Colegio de Sn. Isidoro -hoy Instituto provincial-, donde pintó de perspectiva todos sus retablos. El del altar mayor, especialmente, era una obra maestra de su género».

Y en nota:

«Estaba enfrente del altar mayor que hemos conocido, pues la capilla tenía antes su ingreso por este lado. Al modificarla y trasladar de sitio dicho altar, pintárole al fresco otro retablo de perspectiva infame. Del antiguo, quedaba la mitad superior (por encima del coro) cuando se transformó la capilla en Salón de actos». 48

Según este texto, fue la reforma mandada realizar por Ángel Guirao la que trasladó el altar mayor del testero norte al sur, y, por lo tanto, también el cuadro de San Isidoro. Este cuadro, en su nueva ubicación, se adornó con un retablo pintado de inferior calidad al primitivo, calificado el nuevo de «perspectiva infame», muy distinto de la maestría de las perspectivas de Sistori. El antiguo sólo se podía apreciar en el coro del reformado salón de actos del Instituto.

\section{San Isidoro predicando desde la cátedra}

Preside la nave un cuadro con la imagen del titular del Colegio de Teólogos: San Isidoro de Sevilla. Javier Fuentes y Ponte describe el presbiterio, aunque ignora o simplemente no refiere el presumible cambio de ubicación del altar mayor que hemos señalado.

«En un presbiterio abierto, al que se llega por dos gradas, hay una mesa de celebración correspondiente al gusto moderno, y en su centro se alza un bello y elegante Sagrariotabernáculo cilíndrico, sin columnas ni pilastras, pero cuya decoración es del estilo de la capilla; pues la de dos castillejos de tres gradas cada uno, que hay a sus lados, es del mismo gusto que la mesa de altar».

48 A. BAQuero: Los profesores..., 1913, pp. 271-272. Recoge la noticia en la biografía de Pablo Sistori y nada dice de esto en la de Vicente Inglés. 


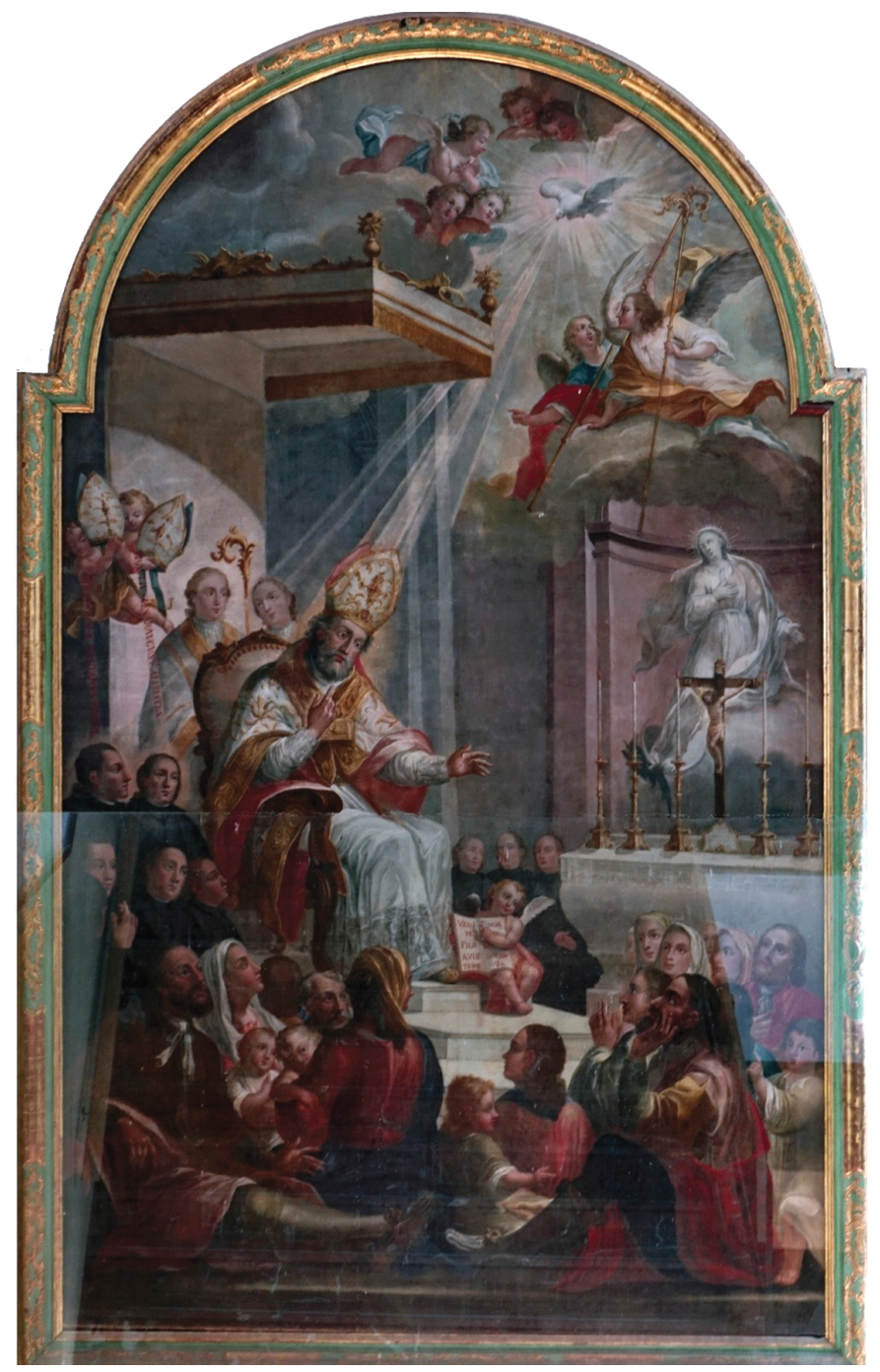

Figura 12. Vicente Inglés. San Isidoro predicando desde la cátedra. Oleo sobre lienzo.

Dimensiones del marco: 402 × $253 \mathrm{~cm}$.

«A la izquierda en un trono y bajo dosel está sentado y vestido de pontifical con mitra, pero sin báculo, el inspirado arzobispo de Sevilla San Isidoro, accionando con ambos brazos el predicar a un gran concurso que hay a sus pies, como a seis colegiales que están a los lados...» (Fuentes y Ponte). 
Sí refiere, en cambio, el pésimo gusto de la pinturas murales de este testero, que no pueden ser, por lo tanto, de Sistori, y que achaca a una inadecuada restauración.

«El frente en su totalidad estuvo pintado al fresco por el famoso D. Pablo Sistori, imitando un pórtico con dos columnas corintias, cornisamento, frontón y ráfaga entre dos jarrones; pero en la actualidad se halla casi destruida por una profanadora restauración de colorido antiartístico».

El cuadro de San Isidoro, destinado al altar mayor, es también el de mayor complejidad compositiva, pues en él aparecen hasta 40 figuras en distintas actitudes y perfectamente individualizadas. Sus medidas son extraordinarias: 4,85 x 2,50 m, incluido el marco, de tal manera que podría ser es el cuadro de mayores dimensiones pintado en Murcia en el siglo XVIII. Su moldura es original, dado su carácter de cuadro único. La composición es muy teatral; seguimos la descripción magistral de Fuentes y Ponte:

\begin{abstract}
«En el centro y lugar preferente de la perspectiva se ve un cuadro en lienzo de $4 \mathrm{~m} .86$ de altura por $2 \mathrm{~m} .14$ de ancho; a la izquierda en un trono y bajo dosel está sentado y vestido de pontifical con mitra, pero sin báculo, el inspirado arzobispo de Sevilla San Isidoro, accionando con ambos brazos el predicar a un gran concurso que hay a sus pies, como a seis colegiales que están a los lados. Detrás del sillón se ven dos eclesiásticos con capa pluvial, teniendo uno el báculo y, no muy lejos de ellos, vuelan dos niños ángeles, cada uno llevando una mitra, habiendo a los pies del santo otro niño ángel sentado y en el acto de abrir un libro».
\end{abstract}

A su izquierda señala:

«El fondo es una perspectiva de iglesia con altar, en cuyas gradas se ven seis candeleros, crucifijo y, en un nicho, la estatua de La Purísima sobre un trono de nubes. En lo alto hay dos serafines, cada cual con báculo, y entre ráfagas aparece el Espíritu Santo». ${ }^{49}$

Por lo tanto, no se trata de una escena del siglo VII sino del XVIII. San Isidoro -revestido de los atributos arzobispales: báculo, mitra, alba blanca y capa pluvial- predica a los estudiantes del Colegio y a un público murciano que asiste al templo. Los receptores del mensaje del santo son dos grupos diferentes:

- Clérigos y colegiales, situados a la izquierda y en segundo plano.

- El pueblo murciano, hombres, mujeres y niños, representado en primer plano, y al que se pueden sumar con naturalidad los espectadores del cuadro, que se incorporan así al mensaje.

49 J. Fuentes y Ponte: España mariana, 1882, pp. 54-55. 
El lienzo contiene también varios epígrafes, que pasamos a transcribir. Las dos mitras situadas a la izquierda del espectador representan a los obispos Braulio de Zaragoza e Ildefonso de Toledo, contemporáneos de San Isidoro, cuyos nombres aparecen en las inscripciones que parten de ellas:

\section{BRAVLIVS CESARAVGVST(ANV)S ANTISTES \\ Braulio obispo cesaraugustano}

\section{ILDEPHONSVS TOLETANVS PRESVL \\ Ildefonso prelado toledano}

Por su parte, un ángel, sentado a los pies del santo, porta un libro abierto en el que se lee:

\section{VENITE FILII AVDITE ME, TIMOR(E)M DO(MINI) DOCEBO VOS Venid, hijos, escuchadme, os instruiré en el temor del Señor} (Salmo 34, 12)

Javier Fuentes y Ponte concluye con una anécdota significativa de la importancia que el Colegio de Teólogos ha tenido en la historia cultural de Murcia. Se trata de la inauguración en noviembre de 1869, delante del cuadro de San Isidoro, de la segunda tentativa de crear una universidad en la ciudad: la Universidad Libre de Murcia (1869-1873), durante el llamado Sexenio Revolucionario:

\footnotetext{
«No pasaremos adelante sin consignar un incidente. Dando la espalda a este altar, y presidiendo un concurrido acto, el primero de Noviembre de 1869, el Excelentísimo Señor Don José Echegaray dijo: "En nombre del ministro más revolucionario, D. Manuel Ruiz Zorrilla, declaró abierta desde este instante la Universidad libre de Murcia", y tal establecimiento fue cerrado en 1873 al proclamarse la república». 50
}

\section{CONSIDERACIONES FINALES}

Desde su fundación en 1767, el relato histórico del Real Colegio de Teólogos de San Isidoro se prolonga más de doscientos cincuenta años. Tras la desamortización de Mendizábal y la creación del Instituto Provincial en 1837, el edifício se convirtió en la sede del primer centro murciano de segunda enseñanza y los cuadros pasaron a formar parte de su patrimonio.

50 J. FuENTE y PonTE: España mariana, 1882, p. 53: «En la planta baja ha estado desde 1869 hasta 1872 la Universidad libre, creada por su primer Secretario Dr. D. González Baños, y de la cual fue Rector el Excmo. Sr. Deán de esta Santa Iglesia, el Dr. D. Jerónimo Torres y Casanova». 
Desde entonces, esta institución se ha denominado Instituto Provincial de Segunda Enseñanza, Instituto General y Técnico y, desde 1939, Instituto Alfonso $\mathrm{X}$ el Sabio, de acuerdo con las diferentes leyes educativas. Después de ciento treinta años de permanencia, en 1966 el Instituto dejó su sede primitiva y se desplazó a un nuevo edificio en el barrio de Vistalegre, trasladándose con todo su patrimonio artístico, documental, científico y didáctico. Recientemente, una exposición en el Archivo General de la Región de Murcia ha recordado los «180 años del Instituto Alfonso X el Sabio». 51

En 2002, durante la dirección de Carlos Collado Mena (2000-2007), se construyó el Museo del Instituto Alfonso X el Sabio (MUSAX) y en él se conserva la mayor parte de este patrimonio artístico y didáctico. Paralelamente se procedió a la restauración de las pinturas por parte del Centro de Conservación y Restauración de Bienes Culturales de la Región de Murcia. Con esta ocasión, los fondos documentales históricos del Instituto se depositaron en el Archivo General de la Región de Murcia. En ambos casos, este patrimonio se encuentran a disposición de toda la sociedad murciana.

\section{BIBLIOGRAFÍA}

AgüEra Ros, José Carlos: Pintores y pintura del Barroco en Murcia, Murcia: Tabularium, 2002.

Arnaldos Martínez, Francisco: «El colegio de teólogos de San Isidoro de Murcia», Scripta Fulgentina, 18, 2008, pp. 141-167.

Baquero Almansa, Andrés: Los profesores de las Bellas Artes murcianos: con una introducción histórica, Murcia: Ayuntamiento de Murcia, 1980 [1913].

Belmonte, Juan José: Murcia artística. (Apuntes literarios), Murcia: Estab. tipográfico de La Paz, 1981.

Catálogo de obras restauradas. 1998 a 2007. Memoria del Centro de Conservación y Restauración de Bienes Culturales de Región de Murcia, Murcia: Dirección General de Bellas Artes y Bienes Culturales, 2008.

Díaz CAssou, Pedro: Serie de los obispos de Cartagena, Instituto Municipal de Cultura: Murcia, 1977 [1895].

El Legado de la pintura, Murcia 1516-1811, Murcia: Ayuntamiento de Murcia 1999. Fuentes Y POnTe, Javier: España Mariana. Provincia de Murcia, Lérida: Imprenta Mariana, 1880-84. Murcia: Fundación Centro de Estudios Históricos e Investigaciones Locales de la Región de Murcia, 2005.

51 La exposición Un legado de conocimiento. 180 años del Instituto Alfonso X el Sabio se ha realizado en el Archivo General de la Región de Murcia del 22 de marzo al 27 de abril de 2018. Disponible en: < http://www.regmurcia.com/eventos/40472>. 
Huellas. Catedral de Murcia. Exposición 2002, Murcia: Caja de Ahorros de Murcia, 2002.

Jiménez MADrid, Ramón (coord.): El instituto Alfonso X el Sabio: 150 años de historia, Murcia: Editora Regional, 1987.

LÓPEZ Azorín, Fernando: Murcia y sus científicos en la Real Sociedad Española de Historia Natural (1871-1940), Murcia: Fundación Séneca, 2012, pp. 101110 .

Miravete Gómez, José Antimo: El antiguo Colegio de Teólogos de San Isidoro, Murcia, 2017.

Moya García, María Luisa: Pablo Sístori. Un pintor italiano en la Murcia del siglo XVIII, Murcia: Academia Alfonso X el Sabio 1983.

RuIz Llamas Gracia \& López García, David: Un programa docente del s. XVIII en Murcia. El pintor Vicente Inglés, Murcia: Academia Alfonso X el Sabio, 2003

Yepes Hita, José Luis; Montojo Montojo, Vicente: «El Colegio de Teólogos de San Isidoro y su legado patrimonial al Instituto Alfonso X el Sabio», XI Jornadas de Institutos Históricos, Murcia, 2017. Disponible en: < http://asociacioninstitutoshistoricos.org/site/andelpih/general-information/communications.html>.

\section{Agradecimientos}

Quiero reconocer la ayuda y las numerosas noticias aportadas para este trabajo por los profesores del Instituto Alfonso X el Sabio, entre los que he de mencionar a Rafael Marín, Ramón Jiménez Madrid, María Ángeles Gómez, Luis Luengo, José Luis Yepes, José Navarro Mateo, Juan Carlos Ferre y, naturalmente, a su director Andrés Nieto Salinas. También quiero agradecer a la Real Academia Alfonso X el Sabio y, en particular, a Santiago Delgado su invitación al ciclo de conferencias dedicadas a los ciento ochenta años de vida del Instituto. 
